\title{
Psychological and pedagogical support for the professional formation of humanities profile students
}

\author{
V.I. Volchkova ${ }^{1 *}$, Z.I. Pavitskaya ${ }^{2}$, and T.K. Sagitdinova ${ }^{3}$ \\ ${ }^{1}$ Volga Region State University of Physical Culture, Sports and Tourism, Kazan, Russia \\ ${ }^{2}$ Volga Region State University of Physical Culture, Sports and Tourism, Kazan, Russia \\ ${ }^{3}$ Volga Region State University of Physical Culture, Sports and Tourism, Kazan, Russia
}

\begin{abstract}
The article considers the need for psychological and pedagogical support for the professional formation of humanities students. It pays special attention not only to the acquired knowledge and skills in the process of studying at the university but also to the acquisition of professional skills and abilities. These abilities allow the student to identify him with the specialists of the chosen profession. The study of the problem of psychological and pedagogical support for the professional formation of students, as well as the development of certain aspects of the implementation of support programs at the university level, are at the stage of discussion and accumulation of empirical material in Russia. It becomes an urgent task to develop the trajectory of psychological and pedagogical support for students, which will allow them to realize higher needs in the field of training and education and build a more successful professional career. This article describes the stages of psychological and pedagogical support of professional formation (adaptation, identification, consulting). The aims, objectives and content of the defined stages are considered, based on which the trajectory of psychological and pedagogical support of professional formation is built. The trajectory was created using a competency-based approach included in the general system of integrated professional training. The effectiveness of the selected trajectory is verified by the means of various techniques.
\end{abstract}

\section{A problem statement}

The problem of preparing humanities profile students for life and professional selfdetermination in modern difficult socio-economic conditions is becoming more urgent. Modern society needs independent, professionally mobile and flexible graduates who can quickly analyze the situation, make decisions and interact with other people. However, as practice shows, many university graduates face serious problems on the path of professional development. These problems include lack of a distribution system for young professionals;

\footnotetext{
*Corresponding author: prof-ped.gpa@mail.ru
} 
the focus of many organizations on achieving current results, rather than on long-term development; lack of mechanisms that ensure the relationship between the labor market and the educational services market; mismatch between the demand of the labor market and the level of practical training of graduates. All this hinders the successful self-realization of a graduate in the labor market, reduces the importance of his profession, and generates anxiety and uncertainty in the future [1].

Young professionals all over the world face high competition due to the lack of knowledge and experience. Besides, in the course of the learning process, teachers and students constantly have to face changes in the requirements for professional training, and the connection between educational institutions and employers is lost [2, 3]. Due to COVID-19, the demand for young employees is decreasing. All these problems and difficulties affect the peculiarities of the professional development of humanities profile students.

\subsection{The objective of the work}

The analysis of the psychological and pedagogical literature has shown that there is a sufficient number of works devoted to the problem of professional formation, and a fairly clear description of its content components is given. However, today not all universities pay due attention to the professional development of students. At the present stage of higher education development, there is a need for psychological and pedagogical support for the professional development of students at the university level [4].

In this regard, the task of developing the content of psychological and pedagogical support for the professional development of students on the basis of a competency-based approach included in the general system of integrated educational content becomes a priority.

The works of domestic and foreign researchers are devoted to the problem of psychological and pedagogical support of professional development: S.A. Leung [5], D.E. Super [6], E.V. Tsirikova [4, 7], Yu.P. Povarjonkov [8], S.A. Morozova [9], E.F. Zeer, [10, 11, 12], L.M. Kulikova [13], S.N. Chistyakova, K.N. Sivtseva, A.R. Atlasova [14], A.E. Emilbekova [15], Yu. P. Kosheleva [16] et al. In foreign science, it began to be developed earlier. In Russian science, the problem of professional formation began to be developed only in the Soviet period.

\section{Results of the research}

According to international forecasts of sociologists, psychologists and teachers, the main and necessary skills and abilities of a specialist in 2025 will be the ability to work with a large amount of information, communication skills, the ability for analytical thinking and innovation, a tendency to retrain in the framework of lifelong education and flexible adaptation in constantly changing life and professional situations. They need to be developed today. In addition, according to the international personnel portal "Headhunter", the specialist of the future must:

- $\quad$ be cross-functional - be able to work at the intersection of professions;

- be a "universal soldier" - know several languages, be able to think creatively;

- be prepared to change 10 professions throughout a lifetime and cross-cultural movements and work in different countries [17].

As reported by V.I. Blinov, the educational community recognizes the need for "4C" literacy: communication, creativity, critical thinking and collaboration [18]. 
In consonance with the above requirements and characteristics, it can be stated that the modern process of professional formation will be more difficult to pass from year to year since it is inseparable from the student's personal development and the socio-economic development of our society. It is very difficult for adolescents and young people to exist in the digital age [19]. They do not always cope with stressful situations and huge information overloads. Moreover, entering a university, they find themselves in an unfamiliar social situation.

According to Yu. P. Povarjonkov, studying at a university is one of the stages of a person's professional formation [8]. The "student" social role is complicated, unfamiliar and polyvalent for young people. In the process of studying at the university, students face difficulties associated with educational activities and personal experiences (lack of selfcontrol habits, separation from parents, replacement of lessons for sessions, change of living conditions) [20]. This determines the importance and necessity of psychological and pedagogical support in this difficult period of personal and professional development. Therefore, it is so important to identify everyone interested in various fields of science, to help them realize their plans and dreams, to more fully reveal their abilities [21].

A conducted survey in the period from 2020 to 2021 of the 3 rd and $4^{\text {th }}$-year students of the Service and Tourism Faculty of the Volga Region State University of Physical Culture, Sports and Tourism (86 participants), showed that $87 \%$ of respondents are aware of the importance and value of professional development. Psychological and pedagogical support must effectively fulfill its main goal: to maximize the personal and professional formation of students. Therefore, the training and education of students at university can be considered as a unified process of socialization, professionalization, and specialization.

In this study, psychological and pedagogical support is understood by the authors as an integral system that provides a comprehensive creation of conditions for the successful socialization and adaptation of students, promoting their personal and self-development. This process is effective only if it corresponds to the goals, objectives and stages of development and is carried out systematically.

Within the framework of this study, psychological and pedagogical support of the professional formation of humanities students will take place in the following fields:

1) Social and psychological adaptation of students to educational and professional activities and the formation of a positive image of their future profession.

2) Correction of students' emotional state, i.e. removal of emotional stress, feelings of anxiety.

3) Formation of skills and abilities of professional communication in various situations.

4) Formation of personal qualities that contribute to successful professional development as a specialist.

Various methods and forms of conducting classes are used: individual, group, and mixed [4].

Psychological and pedagogical support as an integral system consists of the following stages and is implemented in various forms:

The first stage is adaptation. It creates conditions that will facilitate the entry of the 1st year students into the educational process. Forms of implementation: adaptation training, diagnostics of individual psychological characteristics of students, the importance of the life sphere, consultation with students, group advisors, round table discussions, conversation-discussion, and focus group.

The second stage is identification. This is the process of psychological and pedagogical support of the 2nd year students. At this stage, the students' professional knowledge is developed and deepened. Forms of implementation: reflective workshops, training tasks, exercises, and drills. 
The third stage is consultation. This stage involves psychological and pedagogical support of 3rd and 4th year students. During this stage, activities are carried out aimed at solving issues related to the passage of practical training, the choice of specialization, and adaptation in the workplace. Forms of implementation: individual and group consultations, modeling of problem situations, and game methods.

Table 1 shows the trajectory of psychological and pedagogical support for students of the Volga Region State University of Physical Culture, Sports and Tourism. It is based on the principles of determination, consistency, and subjectivity (Table 1).

Table 1. The trajectory of psychological and pedagogical support of the professional formation of students.

\begin{tabular}{|c|c|c|}
\hline Stage & Aims and objectives of the stage & Stage content \\
\hline $\begin{array}{l}\text { Stage } 1- \\
\text { Adaptation }\end{array}$ & $\begin{array}{l}\text { Aim: studying the personal } \\
\text { potential of students. } \\
\text { Objectives: to create the conditions } \\
\text { that facilitate the adaptation } \\
\text { processes of the first-year student; } \\
\text { to increase the resistance level to } \\
\text { stress and intellectual stress; } \\
\text { to raise the awareness of various } \\
\text { aspects of the modern world of } \\
\text { work. }\end{array}$ & $\begin{array}{l}\text { A. Adaptation semester program: } \\
\text { Analysis of the contingent of } \\
\text { applicants and students, identification } \\
\text { of professional intentions and } \\
\text { readiness for training: } \\
\text { Training "Effective student", } \\
\text { "Freshman Training"; } \\
\text { Primary diagnostics of students' } \\
\text { personal potential and their values: } \\
\text { "Communication Training", "Self- } \\
\text { regulation Training", "Conflict } \\
\text { Resolution Training", "Self-confidence } \\
\text { Training"; } \\
\text { Round table discussion "Let's get } \\
\text { acquainted": memo to a freshman, } \\
\text { round table discussion about the } \\
\text { traditions of the Volga Region } \\
\text { University "Welcome to the University } \\
\text { of Champions"; } \\
\text { Volunteer program "Let's Help Our } \\
\text { Friends"; } \\
\text { Organization of collaborative work of } \\
\text { first year and senior students } \\
\text { (scientific, creative, social); } \\
\text { "Advisor's School". } \\
\text { B. The program "Introduction to the } \\
\text { specialty" provides for acquaintance } \\
\text { with the specialty professional activity } \\
\text { via visiting several travel agencies in } \\
\text { Kazan and getting to know the work of } \\
\text { a guide-translator; } \\
\text { Research game "Stalker". }\end{array}$ \\
\hline $\begin{array}{l}\text { Stage } 2- \\
\text { Identification }\end{array}$ & $\begin{array}{l}\text { Aim: personal and professional } \\
\text { development of students. } \\
\text { Objectives: to accustom to the } \\
\text { profession; to form the needs for it. }\end{array}$ & $\begin{array}{l}\text { "My profession, my opportunities and } \\
\text { my achievements"- the program of } \\
\text { student's professional and personal } \\
\text { qualities development: constant } \\
\text { monitoring of the quality of }\end{array}$ \\
\hline
\end{tabular}




\begin{tabular}{|c|c|c|}
\hline & & $\begin{array}{l}\text { professional training of future } \\
\text { specialists: } \\
\text { Round table discussion "Have I really } \\
\text { chosen the profession that I need ..."; } \\
\text { Reflection and diagnostics of personal } \\
\text { development: "What are my real } \\
\text { professional opportunities" - round } \\
\text { table discussion. }\end{array}$ \\
\hline $\begin{array}{l}\text { Stage } 3- \\
\text { Consulting }\end{array}$ & $\begin{array}{l}\text { Aim: personal and professional } \\
\text { formation of students. } \\
\text { Objective: to consolidate } \\
\text { professional, social and personal } \\
\text { self-determination. }\end{array}$ & $\begin{array}{l}\text { "Young Specialist" program: } \\
\text { monitoring the professional success of } \\
\text { young specialists; } \\
\text { Professional trial: professional tests } \\
\text { and professional verification (using the } \\
\text { "Case-study" method and role-playing } \\
\text { games); } \\
\text { Modeling elements of a specific } \\
\text { professional activity; } \\
\text { Advising on professional formation; } \\
\text { Holding round table discussions: "How } \\
\text { to build your professional career?", } \\
\text { "Do I need to continue improving } \\
\text { professionally or not?". }\end{array}$ \\
\hline
\end{tabular}

Psychological and pedagogical support in the form of a practice-oriented program is considered as the creation of favorable conditions for the student to perform professional activities. It contributes to his development as a professional, to the formation of professional needs, value attitudes towards professional knowledge, increased satisfaction with the chosen profession and the development of the necessary professional behavior. In addition, psychological and pedagogical support is a factor that prevents possible risks and deviations in the behavior of students.

Activities under the program of psychological and pedagogical support for the professional formation of humanities students include the following types: methodological, scientific, research and diagnostic, developmental, and consulting [22].

Research activity is one of the most effective ways of teaching and professional formation of students. This is a completely unique process when a teacher and a student become like-minded people. Every year, the Volga Region State Academy of Physical Culture, Sports and Tourism hosts the All-Russian Scientific and Practical Conference of Young Scientists, postgraduates, undergraduates and students "Actual Problems of the Theory and Practice of Physical Culture, Sports and Tourism". This year it was dedicated to the Year of Science and Technology, which is our future. At the sections of this conference, students defend their research papers. Annually at the Department of Foreign Languages and Linguistics, various competitions and contests are held, among them are the following: public speaking contests, and genealogy contests, such as "Battle of linguists", "The best reciters", "Learn to win!"; project competitions, and essays "Smart Academy" quiz, and so on. Thus, the research work at the Department of Foreign Languages and Linguistics of the Volga Region State University also contributes to the professional formation of students. Scientific research is always creativity, and joy of discovering new and interesting things, testing one's intellectual, creative and professional capabilities. 
At the Volga Region State University of Physical Culture, Sports and Tourism, an important means of forming a civic position and developing personal potential is the volunteer movement. In addition, the university has a huge effective experience in training volunteers and participation of students in charitable activities [23].

To test the effectiveness of the program of psychological and pedagogical support for the professional formation of students, a questionnaire of professional readiness was developed. The questionnaire contained 50 questions. Besides, the "Methods of professional readiness" was also used for diagnostics. The students were offered 99 statements. If the student agrees with the statement, then in the answer sheet he puts a "+" sign, if he does not agree, puts a "-". At the end of the program effectiveness test, the students were asked to write an essay "My professional path". They were offered a rough outline for writing an essay: "I want to be", "My abilities", "For this I am doing", and "After graduating I plan". Table 2 provides data on the level of professional readiness on the first and fourth courses.

Table 2. Professional readiness level, (\%).

\begin{tabular}{|l|l|l|l|}
\hline № & Indicator & 1st course & 4th course \\
\hline 1 & $\begin{array}{l}\text { Autonomy and independence in choosing } \\
\text { professional solutions }\end{array}$ & 8 & 71 \\
\hline 2 & $\begin{array}{l}\text { Awareness of various aspects of the modern world } \\
\text { of work and the chosen profession }\end{array}$ & 12 & 79 \\
\hline 3 & $\begin{array}{l}\text { Ability to make professional decisions quickly and } \\
\text { correctly in various situations }\end{array}$ & 6 & 74 \\
\hline 5 & $\begin{array}{l}\text { Ability to plan and use your time efficiently } \\
\text { pmotional value attitude towards the chosen } \\
5\end{array}$ & 19 & 83 \\
\hline
\end{tabular}

According to these results, it can be seen that in 1st year students have the basic knowledge about the world of professions, however, there are many aspects related to the specifics of their profession that are unfamiliar to students. As for the autonomy in the choice of professional decisions, they are able to make them, but they are not fully aware of their responsibility for the choices made. In the 4th year, students formulate more precisely, what they are doing for their professional development; they already know exactly what they want to do after graduating from the university in comparison with the 1st year.

\section{Conclusions}

The research carried out and the qualitative analysis of the data allowed drawing several important conclusions.

Firstly, the psychological and pedagogical support of the professional formation of a student should be an integral, interconnected system of interaction between a teacher and a student. This system is a series of activities based on the acmeological approach, with the use of variable forms of interaction with students, involving such psychological mechanisms as identification, reflection in the processes of observation, discussions, round tables, trainings, consultations, modeling, and mental reproduction of future professional activities.

Secondly, psychological and pedagogical support of professional formation provides the dynamics of such content characteristics as an increase in educational needs (89\%); a change in the perception of oneself as a future representative of the professional community $(78 \%)$; an increase in satisfaction with the chosen specialty $(89 \%)$; the best selfunderstanding (79\%); formation of correct professional behavior (91\%). 
Thirdly, in order to build an optimal trajectory of psychological and pedagogical support of professional development, it is necessary to start from the very beginning that is a moment a young person enters a university and chooses his profession.

\section{References}

1. A.N. Garipova, V.I. Volchkova, Z.I. Pavitskaya, Modern problems of forming professional competence of foreign language teachers in the sport university, Science and Sport: current trends, 4, 99-108 (2018)

2. L.J. Waks, The Concept of Fundamental Educational Change. Educational Theory, 57, 277-295 (2007)

3. F. Carina, Processes of Integration of Higher Level Studies. The case of Teacher Training, Procedia - Social and Behavioral Sciences, 197, 222-227 (2015)

4. E.V. Tsirikova, N.N. Lukanina, Interaction of court with the school social, psychological and pedagogical service, Education and Upbringing, International Scientific Journal, 1(11), 90-94 (2017)

5. S.A. Leung, The Big Five Career Theories. In J.A. Athanasou \& R. Van Esbroek (Eds.), International Handbook of Career Guidance, 115-132 (2018)

6. D.E. Super et al. Vocational Development, A Framework of Research (2007)

7. E.V. Tsirikhova, Improving environmental education through innovations in the activities of teachers as the basis for the implementation of the system of health preservation of schoolchildren, Materials of the $\mathrm{V}$ International scientific and practical conference "Health preservation as an innovative aspect of modern education", 429-436 (2019)

8. Yu.P. Povarjonkov, Systemogenetic analysis to professional development of the individual, Organizational psychology and labor psychology, Institute of Psychology of the Russian Academy of Sciences, 2(4), 4-39 (2017)

9. S.A. Morozova, The process model of the teacher musical-pedagogic preparation to cultural and educational activities, Bulletin of Kostroma State University named after. N.A. Nekrasov, 2, 201-205 (2016)

10. E.F. Zeer, M.V. Zinnatova, Conflicting realities of professional development of teachers in the conditions of transformation of educational organizations, Professional education and the labour market, 1(40), 75-84 (2020)

11. E.M. Dorozhkin, E.F. Zeer, Research and educational panorama of modernization of training teachers of continuous vocational education, The Education and Science Journal, 19(1), 167-171 (2019)

12. E.F. Zeer, Self-Adjustable Doctrine as Psychological and Didactic Technology of Students' Competence Forming, Psychological Science and Education, 9(3), 5-11 (2004)

13. L.M. Kulikova, Competences slant in professional preparation of High school physical culture student, Science and Sport: current trends, 1(2), 6-51 (2014)

14. S.N. Chistyakova, K.N. Sivtseva, A.R. Atlasova, Trends in the development of vocational guidance for students and challenges of the time, Scientific and methodological electronic journal "Concept", 26 (2017)

15. A.E. Emilbekova, Professional development and dynamics of professional identity at different stages of personality development, Vestnik of Moscow State Linguistic University. Education and Teaching, 1(790), 153-164 (2018) 
16. Yu.P. Kosheleva, Students' goal professional identity in higher school, Vestnik of Moscow State Linguistic University. Education and Teaching, 1(770), 36-46 (2017)

17. M.I. Vinnikova, Z.I. Pavitskaya, Modernization of forms and methods of teaching in pedagogical universities in Germany at the present stage, Collection of scientific articles of the scientific-practical conference "Anthropological knowledge as a system-forming factor of professional pedagogical education", 304-306 (2019)

18. V.I. Blinov, E.Yu. Yesenina, Development of secondary vocational education: scenario and forecasts, Vocational education. Capital, 3, 5-8 (2015)

19. V.I. Volchkova, Linguistic and cultural activities at the lessons of Russian as a foreign language in the modern Higher School, Science and Sport: current trends, 4, 130-133 (2018)

20. S.E. Nikitina, M.N. Vinnikova, G.F. Dulmukhametova, Z.I. Pavitskaya, Methodical model of professional communication training of students on the English lessons, Opcion, 34, 99-108 (2018)

21. T.V. Khristidis, Psycho-pedagogical support of students at the university, The Bulletin of Moscow State University of Culture and Arts, 1 (2015)

22. Jh.I. Aytuganova, M.N. Vinnikova, Z.I. Pavitskaya, Use of the pedagogical technology "Team-Teaching" in the training of future teachers in Germany, The Bulletin of Kazan State Power Engineering University, 2(34), 125-130 (2017)

23. A.M. Galimov, G.F.Ageeva, Sports-based charitable activities in Russia, Science and Sport: current trends, 9(1), 82-88 (2018) 